\title{
Damping characteristics of TiNi binary and ternary shape memory alloys
}

\author{
S.K. Wu ${ }^{\mathrm{a}, *}$ H.C. $\operatorname{Lin}^{\mathrm{b}}$ \\ ${ }^{\mathrm{a}}$ Department of Materials Science and Engineering, National Taiwan University, Taipei 106, Taiwan \\ ${ }^{\mathrm{b}}$ Department of Materials Science, Feng Chia University, Taichung 407, Taiwan
}

\begin{abstract}
High damping materials are currently attracting much attention in engineering applications. TiNi shape memory alloys (SMAs) could exhibit high damping capacity, as well as excellent shape memory effect and superelasticity. The high damping capacity of TiNi SMAs is mainly related to the hysteretic movement of martensite variants, twin planes and parent-martensite interfaces. The addition of a third element has a substantial effect on the damping capacity of TiNi SMAs. In this paper, the damping characteristics of the binary and ternary TiNi SMAs are systematically investigated. Also, effects of alloy's microstructures and crystal defects on damping characteristics of TiNi SMAs are discussed.
\end{abstract}

(C) 2003 Elsevier Science B.V. All rights reserved.

Keywords: Intermetallics; Surfaces and interfaces; Strain

\section{Introduction}

TiNi alloys are known as the most important shape memory alloys (SMAs) because of their many applications based on the shape memory effect (SME) and pseudoelasticity (PE). This comes from the fact that TiNi alloys have superior properties in ductility, fatigue, corrosion resistance, biocompatibility and recoverable strain, etc. It is also reported that TiNi alloys can exhibit a high mechanical damping and are promising for the energy dissipation applications [1-5]. Damping mechanisms, in general, involve the stress-induced movement of defects. For high-damping metals, the major mechanisms are the stress-induced movement of dislocations or planar defects [6]. Most of these mechanisms can be phenomenologically split into three classes: dynamic hysteresis, static hysteresis, and transformation mechanisms. Dynamic hysteresis is produced by the stress-aided ordering of defects overcoming local barriers by thermal activation and yields damping that is frequency dependent and amplitude independent. Static hysteresis appears due to the stressinduced 'unpinning' or 'break-away' process of the defects [6-8], and yields damping that is frequency independent and amplitude dependent. Some metals exhibit a high level of damping in the region of a transformation, for example,

\footnotetext{
*Corresponding author. Tel.: +886-2-2363-7846; fax: +886-2-23634562.

E-mail address: skw@ccms.ntu.edu.tw (S.K.Wu).
}

in the temperature range of a thermoelastic martensitic transformation $[9,10]$. Such thermoelastic damping is frequently amplitude independent and proportional to the transformation rate. In this paper, by using both flexural resonant-bar and low frequency inverted torsion pendulum techniques [11], the damping characteristics of TiNi binary and ternary SMAs are investigated in the high-temperature cubic B2 phase, the low temperature monoclinic B19' martensite, and the intermediate rhombohedral $\mathrm{R}$ phase or orthorhomic B19 phase. The dominant damping mechanisms occurring in these phases and the characteristics associated with the thermoelastic transformations of TiNi SMAs are also discussed.

\section{Low-frequency internal friction damping}

Fig. 1a and $\mathrm{b}$ show the internal friction $Q^{-1}$ of $\mathrm{Ti}_{49.8} \mathrm{Ni}_{50.2}$ alloy and $400{ }^{\circ} \mathrm{C} \times 5 \mathrm{~h}$ aged $\mathrm{Ti}_{49} \mathrm{Ni}_{51}$ alloy as a function of temperature, respectively. In Fig. 1b, peaks $\mathrm{P}_{\mathrm{H} 1}$ and $\mathrm{P}_{\mathrm{H} 2}$ appear in heating and peaks $\mathrm{P}_{\mathrm{C} 1}$ and $\mathrm{P}_{\mathrm{C} 2}$ appear in cooling. It has been confirmed $[3,11]$ that peaks $\mathrm{P}_{\mathrm{H} 2}$ and $\mathrm{P}_{\mathrm{C} 2}$ are associated with the $\mathrm{B} 2 \leftrightarrow \mathrm{R}$ transformation and peaks $\mathrm{P}_{\mathrm{H} 1}$ and $\mathrm{P}_{\mathrm{C} 1}$ are associated with the $\mathrm{R} \leftrightarrow \mathrm{B} 19^{\prime}$ transformation. All these peaks also correspond to the minima of frequency [3], indicating that the lattice softening phenomenon occurs during these transformations. Fig. $2 \mathrm{a}$ and $\mathrm{b}$ show the frequency and internal friction of $\mathrm{Ti}_{50} \mathrm{Ni}_{40} \mathrm{Cu}_{10}$ alloy as a function of temperature, respec- 

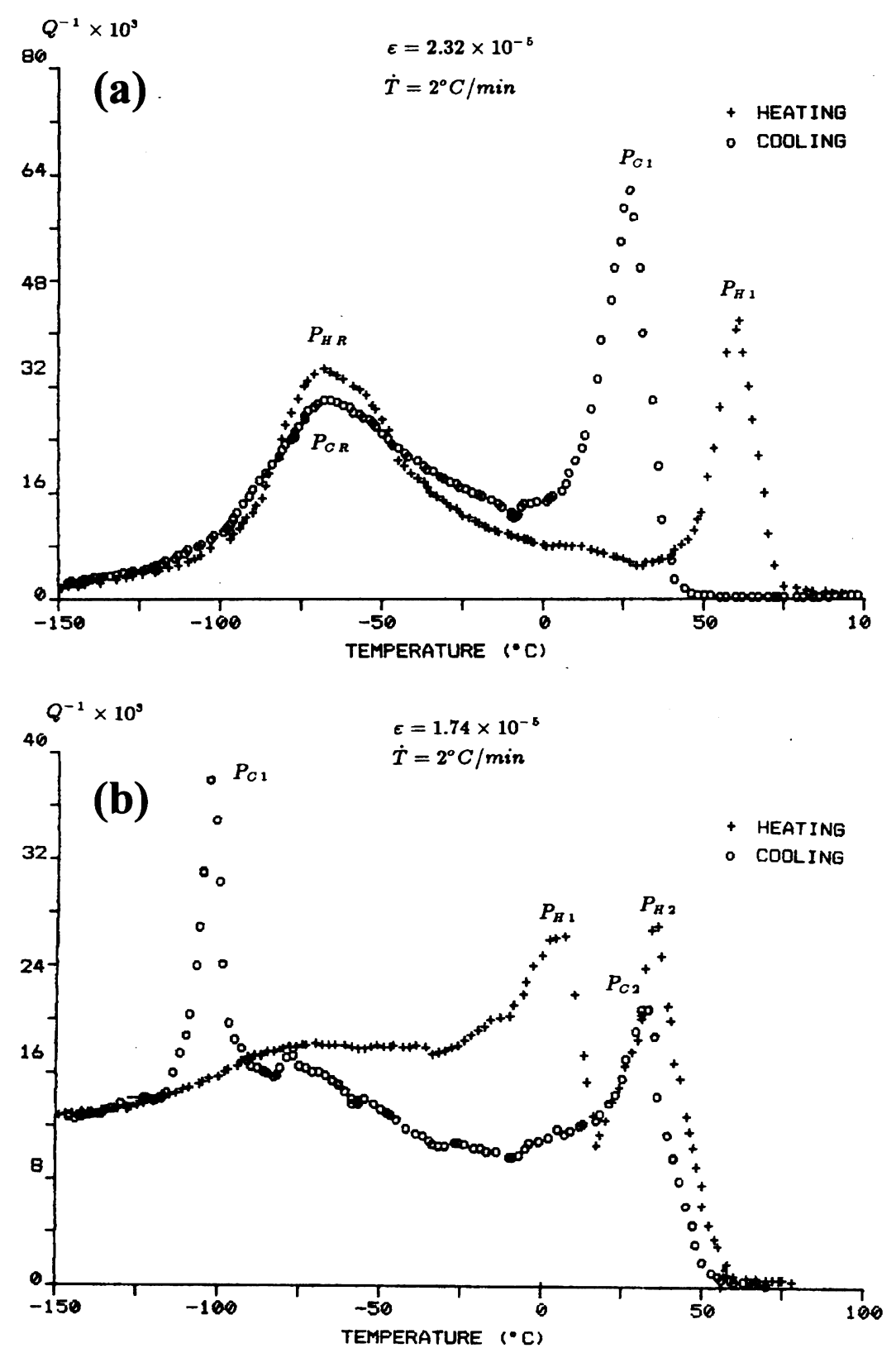

Fig. 1. The internal friction vs. temperature curves for (a) $\mathrm{Ti}_{49.8} \mathrm{Ni}_{50.2}$ alloy, (b) $400{ }^{\circ} \mathrm{C} \times 5$-h aged $\mathrm{Ti}_{49} \mathrm{Ni}_{51}$ alloy.

tively. In Fig. 2b, there are two sharp peaks, $\mathrm{P}_{\mathrm{C} 1}$ and $\mathrm{P}_{\mathrm{C} 2}$, on cooling, and two sharp peaks, $\mathrm{P}_{\mathrm{H} 1}$ and $\mathrm{P}_{\mathrm{H} 2}$, on heating. These peaks correspond to wide frequency minimum plateaus, as shown in Fig. 2a. Peaks $\mathrm{P}_{\mathrm{C} 2}$ and $\mathrm{P}_{\mathrm{H} 2}$ are associated with the $\mathrm{B} 2 \leftrightarrow \mathrm{B} 19$ transformation, while peaks $\mathrm{P}_{\mathrm{C} 1}$ and $\mathrm{P}_{\mathrm{H} 1}$ are associated with the $\mathrm{B} 19 \leftrightarrow \mathrm{B} 19^{\prime}$ transformation [12].

From Figs. 1 and 2, one can find that both martensite and $\mathrm{R}$ phase exhibit the same order of damping capacity which is larger than the B2 phase, and the highest damping capacity appears in the transformation regions in $\mathrm{TiNi}$ SMAs. Furthermore, the $Q_{\max }^{-1}$ for peaks of $\mathrm{B} 19 \leftrightarrow \mathrm{B} 19^{\prime}$ transformation in $\mathrm{Ti}_{50} \mathrm{Ni}_{40} \mathrm{Cu}_{10}$ alloy can reach 0.14 , which is ultrahigh as compared to those of the TiNi binary alloys. As mentioned above, most damping mechanisms involve the stress-induced movement of defects. Point defects give rise to damping in the range of low to intermediate levels, line defects give rise to damping levels in the intermediate to high range, and planar defects give rise to damping levels in the high range. It is well known that there are abundant twin boundaries in the B19/B19' martensite and $\mathrm{R}$ phase of TiNi SMAs [13,14]. These twin boundaries can be easily moved by the external stress to accommodate the strain. The stress-strain diagram for the accommodation process during the damping test is schematically drawn in Fig. 3. It is shown that after an elastic response to the stress, an accommodated strain $\varepsilon_{\mathrm{a}}$ in some microdomains can be produced at a critical value of the stress, $\sigma_{\mathrm{a}}$. This strain is due to the stress-induced movement of twin boundaries between the variants of 

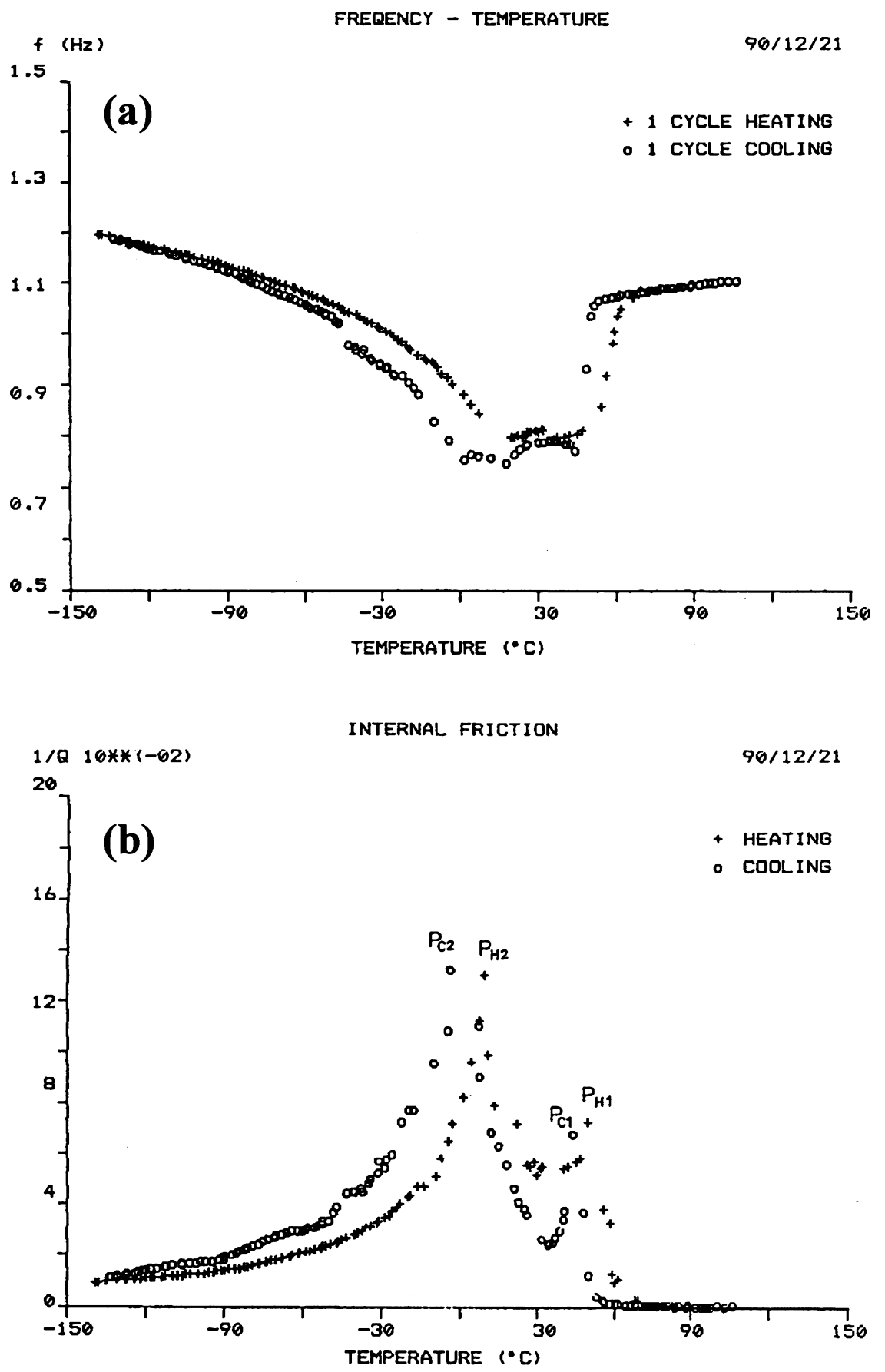

Fig. 2. (a) Frequency, (b) internal friction vs. temperature curves for the $\mathrm{Ti}_{50} \mathrm{Ni}_{40} \mathrm{Cu}_{10}$ alloy.

martensite or $\mathrm{R}$ phase. The accommodated strain is retained during the unloading but can be reoriented to the opposite direction due to the movement of twin boundaries induced by the following opposite-direction stress, $-\sigma_{\mathrm{a}}$. This opens up a relatively large hysteresis loop, $\Delta W$, for the cyclic movement of twin boundaries. Therefore, the martensite and $\mathrm{R}$ phase of TiNi SMAs have a higher damping capacity. No twin boundaries exist in the parent B2 phase of TiNi SMAs, and the damping capacity is suggested simply to come from the dynamic/static hyster- esis of lattice defects, such as vacancy, interstitial or dislocation. Because the dynamic/static hysteresis of lattice defects generally dissipates a smaller quantity of energy, the damping capacity in the B2 phase of TiNi SMAs is smaller.

In Figs. 1 and 2, there are peaks of damping capacity in the transformation regions. The maximum value of the damping capacity occurring in the temperature ranges of transformation is two times or even higher than that occurring in martensite or $\mathrm{R}$ phase. Delorme et al. [15] 


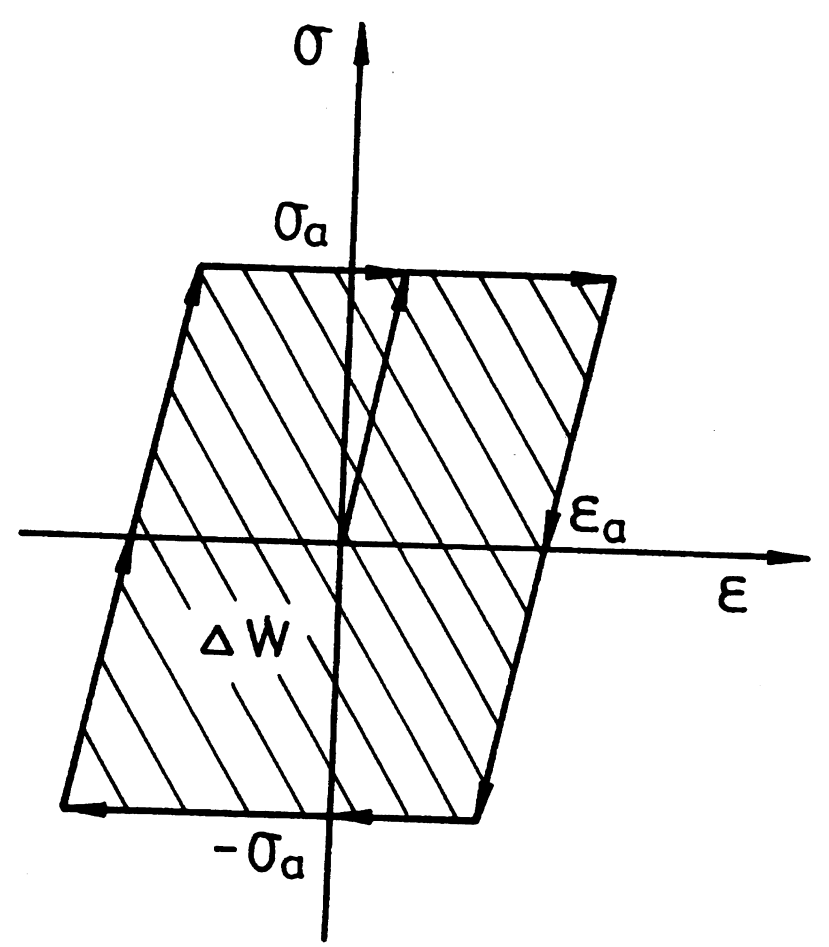

Fig. 3. Schematic stress-strain diagram for the martensite/R phase accommodation process. $\Delta W$ indicates the energy loss for the cyclic movement of twin boundaries.

have shown that all the first-order phase transformations should be accompanied with internal friction peaks and have deduced the internal friction factor $Q^{-1}$ as a function of temperature changing rate $\mathrm{d} T / \mathrm{d} t$, as shown in Eq. (1):

$Q^{-1}=1 / \omega \mathrm{d} \psi\left(V_{\mathrm{m}}\right) / \mathrm{d} V_{\mathrm{m}} \mathrm{d} V_{\mathrm{m}} / \mathrm{d} T \mathrm{~d} T / \mathrm{d} t$

where $V_{\mathrm{m}}$ is the volume fraction of martensite, $\omega$ is the angular frequency of applied stress, and $\psi\left(V_{\mathrm{m}}\right)$ is a monotonic function associated with the transformation volume change and/or shape strain. Eq. (1) indicates that the internal friction factor $Q^{-1}$ is proportional to the heating and cooling rate, $\mathrm{d} T / \mathrm{d} t$. Dejonghe et al. [16], in order to take account of the special character of the martensite which can be induced or reoriented by an external stress $\sigma$, introduced the stress dependence to $\mathrm{d} V_{\mathrm{m}} / \mathrm{d} t$ as follows:

$\mathrm{d} V_{\mathrm{m}} / \mathrm{d} t=\partial V_{\mathrm{m}} / \partial T \partial T / \partial t+\partial V_{\mathrm{m}} / \partial \sigma \partial \sigma / \partial t$

In Eq. (2), the first term is identical to the Delorme's model and the second term is the stress-dependent one. In Fig. 4, an approximately linear variation of peak heights $Q_{\max }^{-1}$ of $\mathrm{P}_{\mathrm{H} 1}, \mathrm{P}_{\mathrm{C} 1}, \mathrm{P}_{\mathrm{H} 2}$, and $\mathrm{P}_{\mathrm{C} 2}$ vs. $\mathrm{d} T / \mathrm{d} t(\mathrm{~d} T / \mathrm{d} t=1,2$, $3{ }^{\circ} \mathrm{C}$ min $^{-1}$ ) for TiNi SMAs is observed. This result indicates that both martensitic and R-phase transformations agree with the Delorme's model at $\mathrm{d} T / \mathrm{d} t=1$ to $3{ }^{\circ} \mathrm{C} \min ^{-1}$. Besides, in Fig. 4, as $\mathrm{d} T / \mathrm{d} t$ is extrapolated to zero, the peak heights are higher than the background. At $\mathrm{d} T / \mathrm{d} t=0$, no martensite or $\mathrm{R}$ phase is formed by a thermal

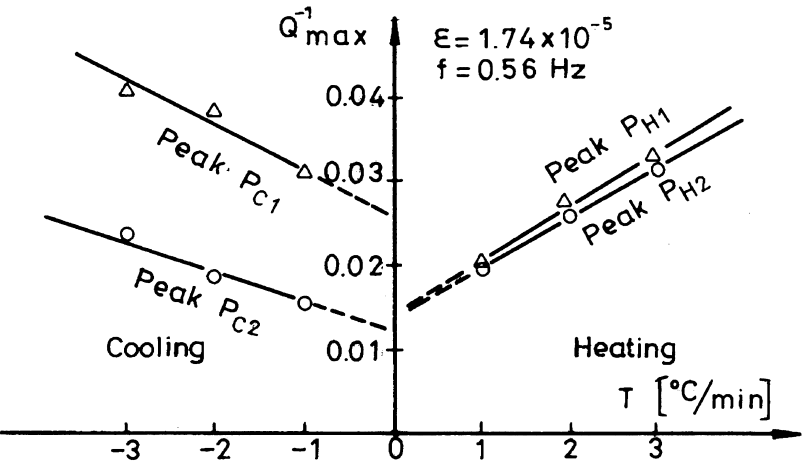

Fig. 4. The internal friction peak heights $Q_{\max }^{-1}$ vs. temperature changing rate $(\mathrm{d} T / \mathrm{d} t)$ for the $400{ }^{\circ} \mathrm{C} \times 5$-h aged $\mathrm{Ti}_{49} \mathrm{Ni}_{51}$ alloy.

driving force, but either can be formed by the applied external stress. In TiNi SMAs, the deformation behavior shows that the stress-induced transformation occurs before the reorientation of variants of martensite or $\mathrm{R}$ phase in the temperature range of forward transformations on cooling [17]. Hence, the damping capacity appearing at $\mathrm{d} T / \mathrm{d} t=0$ on cooling, as shown in Fig. 4, is ascribed to the stressinduced transformation. Tadaki et al. [18] have reported that the volume change and shape strain associated with the martensitic transformation are much larger than those associated with the R-phase transformation. Based on this report, $\mathrm{d} \psi\left(V_{\mathrm{m}}\right) / \mathrm{d} V_{\mathrm{m}}$ for martensitic transformation is larger than that for R-phase transformation. Therefore, the internal friction of the $\mathrm{R} \rightarrow \mathrm{M}$ transformation should be much larger than that of the $\mathrm{B} 2 \rightarrow \mathrm{R}$ transformation. Therefore, the $\mathrm{P}_{\mathrm{C} 1}$ peak $(\mathrm{R} \rightarrow \mathrm{M})$ at $\mathrm{d} T / \mathrm{d} t=0$ is much higher than the $\mathrm{P}_{\mathrm{C} 2}$ peak $(\mathrm{B} 2 \rightarrow \mathrm{R})$ at the same strain amplitude. However, in the heating process, the existing martensite or R-phase variants should be reoriented to accommodate the applied strain. As discussed above, the damping capacities due to the stress-induced movement of the twin boundary in the accommodation process for martensite and $\mathrm{R}$ phase have nearly the same magnitude. Hence, the peak heights $Q_{\max }^{-1}$ of $\mathrm{P}_{\mathrm{H} 1}$ and $\mathrm{P}_{\mathrm{H} 2}$ at $\mathrm{d} T / \mathrm{d} t=0$ have nearly the same values, as shown in Fig. 4.

\section{High-frequency resonant-bar damping}

In order to understand the high-frequency damping property of TiNi SMAs, the flexural resonant-bar damping tests were carried out at various temperatures in which TiNi SMAs exhibit different phases during cooling and heating cycles. Figs. 5 and 6 show the damping capacity $\delta$ vs. temperature and resonant frequency $f$ vs. temperature, for $\mathrm{Ti}_{50} \mathrm{Ni}_{50}$ and $\mathrm{Ti}_{50} \mathrm{Ni}_{40} \mathrm{Cu}_{10}$ alloys, respectively. Fig. 5a shows the frequency minima in the temperature ranges of B2 $\leftrightarrow$ B19' transformation during the cooling and heating cycles for the $\mathrm{Ti}_{50} \mathrm{Ni}_{50}$ alloy. Fig. 5b shows that the damping capacity of $\mathrm{B} 19^{\prime}$ martensite is larger than that of the B2 phase. Meanwhile, a damping peak appears in the 

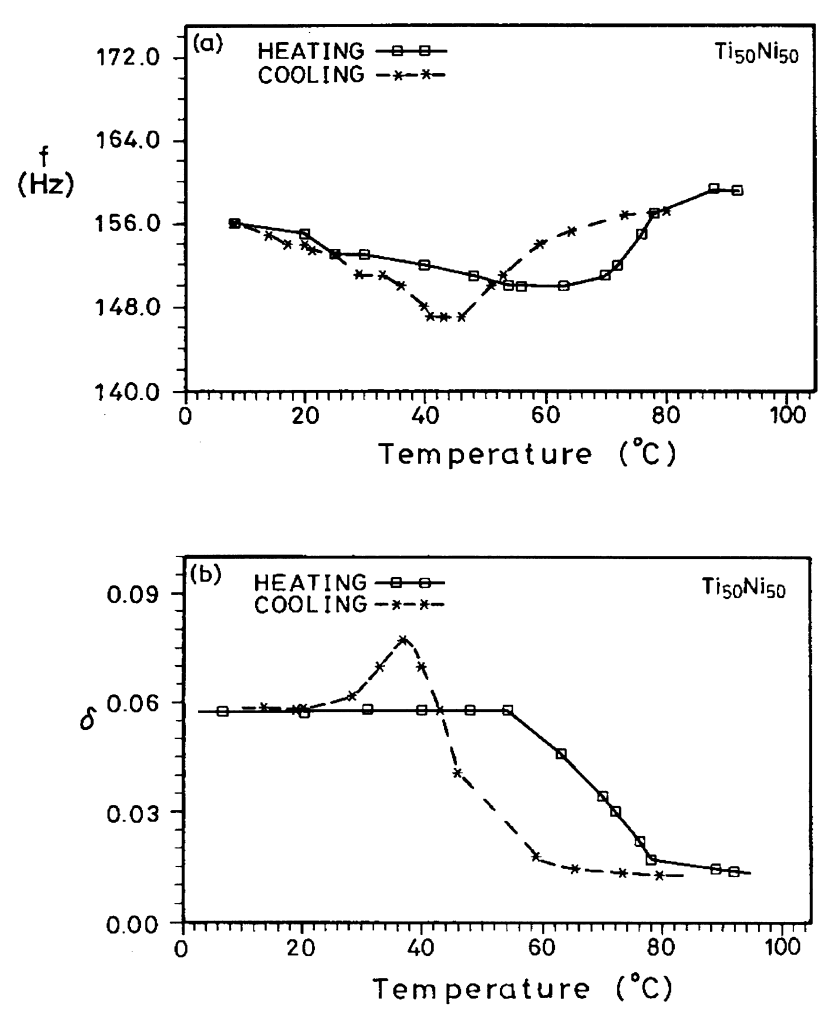

Fig. 5. (a) The resonant frequency $f$ and (b) the damping capacity $\delta$ vs. temperature curves for the $\mathrm{Ti}_{50} \mathrm{Ni}_{50}$ alloy.
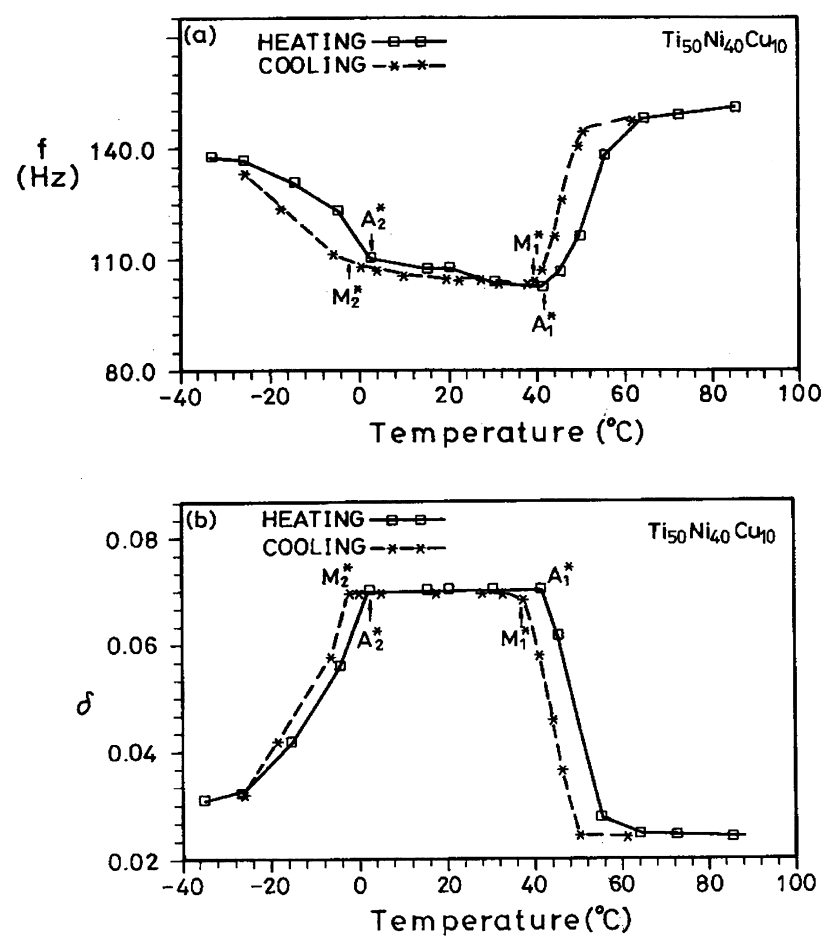

Fig. 6. (a) The resonant frequency $f$ and (b) the damping capacity $\delta$ vs. temperature curves for the $\mathrm{Ti}_{50} \mathrm{Ni}_{40} \mathrm{Cu}_{10}$ alloy. temperature range of $\mathrm{B} 2 \rightarrow \mathrm{B} 19^{\prime}$ transformation, although it is not significant during the $\mathrm{B} 19^{\prime} \rightarrow \mathrm{B} 2$ reverse transformation. In Fig. 6a for the $\mathrm{Ti}_{50} \mathrm{Ni}_{40} \mathrm{Cu}_{10}$ alloy, wide frequency minimum plateaus are observed in the temperature ranges of $\mathrm{M}_{1}^{*}$ to $\mathrm{M}_{2}^{*}$ on cooling and $\mathrm{A}_{1}^{*}$ to $\mathrm{A}_{2}^{*}$ on heating. In the same temperature ranges $\left(M_{1}^{*}\right.$ to $M_{2}^{*}$ and $A_{1}^{*}$ to $\left.A_{2}^{*}\right)$, there are plateaus for high damping capacity, as shown in Fig. $6 \mathrm{~b}$.

Mercier et al. [19], Lotkov et al. [20] and Ren et al. [21] investigated the anomalies of elastic properties of $\mathrm{TiNi}$ binary and ternary single crystals. They reported that the lattice-softening phenomenon promotes shear transformation due to thermal or mechanical driving forces and forms a minimum yield stress around the $M_{\mathrm{s}}$ temperature. This means that, during the martensitic transformation, the movement of twin boundaries or martensite/parent interfaces is easy and most of the energy is dissipated in the transformation region. This causes the peak of damping capacity to appear in the transformation region, as shown in Fig. 5 for the $\mathrm{Ti}_{50} \mathrm{Ni}_{50}$ alloy. However, no damping capacity peak occurs on heating in Fig. 5. The damping capacity maintains a nearly constant value and then gradually decreases to a lower value after B19' martensite has transformed to B2 parent phase. This phenomenon can be explained as follows. In the resonant-bar test $(\mathrm{d} T / \mathrm{d} t=$ 0 ), the damping capacity peak associated with the forward transformation of $\mathrm{B} 2 \rightarrow \mathrm{B} 19^{\prime}$ can be attributed to both stress-induced transformation and stress-induced twin accommodation. The lattice softening can promote stressinduced transformation and increase damping capacity. However, during reverse transformation, the damping capacity can only be contributed by the stress-induced twin accommodation because there is no obvious softening phenomenon on heating [22], and stress-induced reverse transformation is difficult. In other words, during the reverse transformation, the damping capacity arises from the movement of twin boundaries existing in the martensite. Therefore, the damping capacity on heating maintains a near-constant value and then decreases to a lower value after the martensite has transformed to the B2 parent phase.

Fig. 6 shows that the $\mathrm{Ti}_{50} \mathrm{Ni}_{40} \mathrm{Cu}_{10}$ alloy has high plateaus of damping capacity $\delta$ in the temperature ranges of B19 martensite on both cooling and heating cycles. As discussed in a previous paper [12], the B2 $\rightarrow$ B19 transformation should exhibit a dramatic lattice-softening phenomenon because the yielding stress decreases significantly during the transformation. Hence, related to the stress-induced transformation and stress-induced twin accommodation, the damping capacity can increase rapidly during the $\mathrm{B} 2 \rightarrow \mathrm{B} 19$ transformation. Meanwhile, as reported in Ref. [12], the yielding stress of B19 martensite maintains such a low value with temperature variation of $M_{1}^{*}$ to $M_{2}^{*}$. This indicates that the movement of twin boundaries is always quite easy in the temperature range of B19 martensite, hence, the damping capacity maintains a 


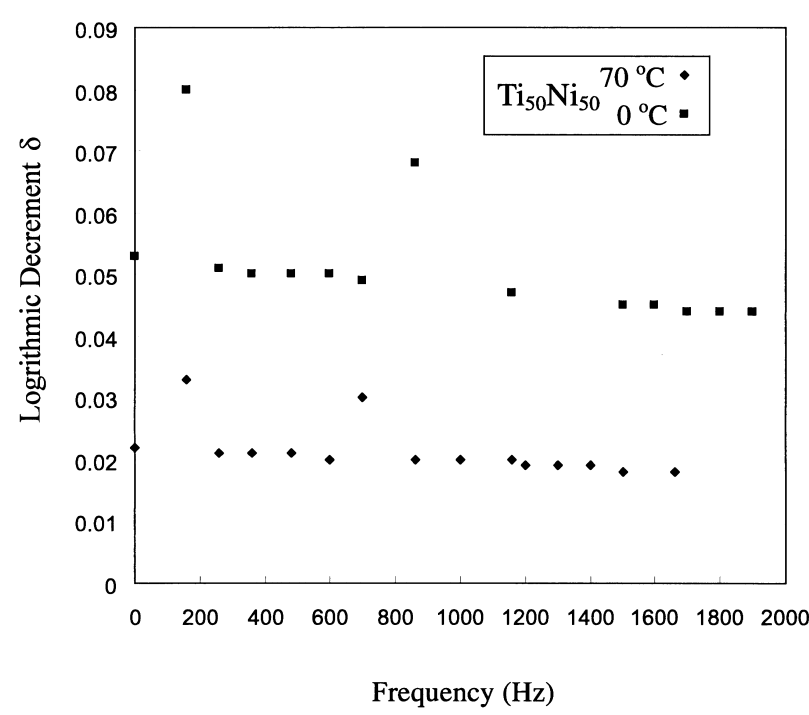

Fig. 7. The damping capacity $\delta$ vs. testing frequency for $\mathrm{Ti}_{50} \mathrm{Ni}_{50}$ alloy at at 0 and $70{ }^{\circ} \mathrm{C}$.

high plateau. Because the yielding stress of B19' martensite is higher than that of B19 martensite, the movement of twin boundaries in $\mathrm{B} 19^{\prime}$ martensite is more difficult than that in B19 martensite. This causes the damping capacity to be lower after the transformation of $\mathrm{B} 19 \rightarrow \mathrm{B} 19^{\prime}$ occurs. On heating, the damping capacity increases rapidly with the increasing transformation volume of $\mathrm{B} 19^{\prime} \rightarrow \mathrm{B} 19$ and then maintains a high plateau which is similar to that on cooling. This is reasonable because, in the B19 region on the heating or cooling cycles, the damping capacities come from a similar mechanism, that is, movement of the twin boundaries in B19 martensite. When B19 martensite gradually transforms to B2 parent phase, the damping capacity also gradually decreases to the lower value of B2 parent phase.

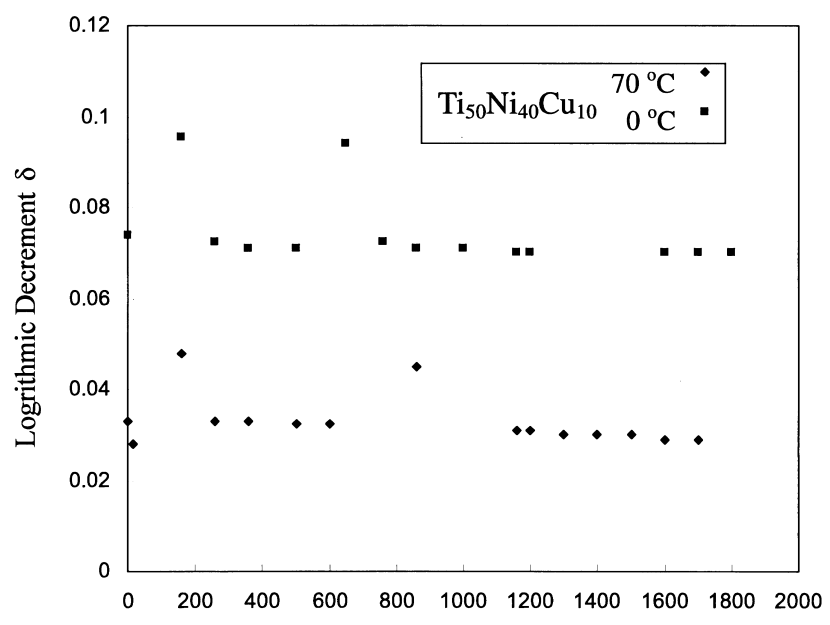

Frequency $(\mathrm{Hz})$

Fig. 8. The damping capacity $\delta$ vs. testing frequency for $\mathrm{Ti}_{50} \mathrm{Ni}_{40} \mathrm{Cu}_{10}$ alloy at 0 and $70^{\circ} \mathrm{C}$.
To understand the frequency effect on the damping property of TiNi SMAs, the flexural resonant-bar damping tests were carried out at frequencies of $0-2000 \mathrm{~Hz}$. The damping capacity (indicated by the logarithmic decrement $\delta$ ) vs. testing frequency are presented in Figs. 7 and 8 for the $\mathrm{B} 19^{\prime}$ martensite and $\mathrm{B} 2$ parent phase of $\mathrm{Ti}_{50} \mathrm{Ni}_{50}$ and $\mathrm{Ti}_{50} \mathrm{Ni}_{40} \mathrm{Cu}_{10}$ alloys, respectively. Careful examination of Figs. 7 and 8 finds that, except at the resonant frequencies, the testing frequency has only slight effect on the damping capacity of TiNi SMAs, no matter in their B19' martensite or B2 parent phase. This frequency-independent phenomenon indicates that the damping capacity of TiNi SMAs predominantly originates from the static hysteresis due to the stress-induced 'unpinning' or 'break-away' process of the defects [6-8].

\section{Conclusion}

Damping characteristics of TiNi SMAs have been systematically studied by using resonant-bar and low frequency inverted torsion pendulum techniques. Both B19/B19' martensite and R phase have high damping capacities due to the stress-induced movement of twin boundaries. The parent B2 phase has a smaller damping capacity which is suggested simply to come from the dynamic/static hysteresis of lattice defects. In the transformation regions, there are damping capacity maxima which are two or more times higher than the damping capacity of martensite or $\mathrm{R}$ phase. Two contributions account for the occurrence of the maxima of damping capacity. One arises from the plastic strain and twininterface movement during the thermal-induced transformation, and the other originates from the stress-induced transformation caused by the applied external stress.

In the resonant-bar test, the damping capacity peak associated with the forward $\mathrm{B} 2 \rightarrow \mathrm{B} 19^{\prime}$ transformation of $\mathrm{Ti}_{50} \mathrm{Ni}_{50}$ alloy is attributable to both stress-induced transformation and stress-induced twin accommodation. However, no peak appears during reverse transformation because there is no obvious softening phenomenon on heating, and the damping capacity can only be produced by the stress-induced twin accommodation. The $\mathrm{Ti}_{50} \mathrm{Ni}_{40} \mathrm{Cu}_{10}$ alloy has high plateaus of damping capacity in the temperature ranges of B19 martensite on both cooling and heating cycles. These high damping capacity plateaus arise from the easy movement of the twin boundaries of B19 martensite because its yielding stress remains at a remarkably low value with temperature variation. The testing frequency has only slight effect on the damping capacity of TiNi SMAs. This frequency-independent phenomenon indicates that the damping capacity of TiNi SMAs predominantly originates from the static hysteresis due to the stress-induced 'unpinning' or 'break-away' process of the defects. 


\section{Acknowledgements}

The authors sincerely acknowledge the financial support of this research by National Science Council (NSC), Taiwan, under Grants NSC82-0405-E002-080 and NSC902216-E002-030. The authors thank Dr T.S. Chou, Landsfair Technology Corporation, Taiwan for his excellent assistance in the internal friction measurement.

\section{References}

[1] K. Iwasaki, R. Hasiguti, Trans. JIM 28 (1987) 363.

[2] O. Mercier, K.N. Melton, Acta Metall. 27 (1979) 1467.

[3] S.K. Wu, H.C. Lin, T.S. Chou, Acta Metall. 38 (1990) 95.

[4] C.M. Jackson, H.J. Wanger, R.J. Wasilewski, NASA-SP 5110 (1972) 35.

[5] D.E. Hodgson, Mater. Sci. Forum 394-395 (2002) 69.

[6] I.G. Ritchie, Z.L. Pan, Metall. Trans. A 22 (1991) 607.

[7] A.S. Nowick, B.S. Berry, Anelastic Relaxation in Crystalline Solids, Academic Press, New York, 1972, 176 pp.

[8] D.W. James, Mater. Sci. Eng. 4 (1969) 1.

[9] R. de Batist, J. Phys. C (1983) 4-39.
[10] J. Van Humbeek, in: Proceedings of the ASM Materials Week and TMS/AIME Fall Meeting, Role of Interfaces on Materials Damping, ASM, Materials Park, OH, 1985, p. 5.

[11] H.C. Lin, S. K Wu, M.T. Yeh, Metall. Trans. A 24 (1993) 2189.

[12] H.C. Lin, S.K. Wu, Y.C. Chang, Metall. Trans. A 26 (1995) 851.

[13] T. Saburi, S. Nenno, in: Proceedings of the International Conference on Solid to Solid Phase Transformation, ASM, Materials Park, OH, 1982, p. 1455.

[14] S. Miyazaki, C.M. Wayman, Acta Metall. 36 (1988) 181.

[15] J.F. Delorme, R. Schmid, M. Robin, P. Gobin, J. Phys. C 32 (1971) $2-101$.

[16] W. Dejonghe, R. de Batist, L. Delaey, Scripta Metall. 10 (1976) 1125.

[17] S. Miyazaki, K. Otsuka, Metall. Trans. A 17 (1986) 53.

[18] T. Tadaki, Y. Nakata, K. Shimizu, Trans. JIM 28 (1987) 883.

[19] O. Mercier, K.N. Melton, G. Gremaud, J. Hagi, J. Appl. Phys. 41 (1980) 1833.

[20] A.I. Lotkov, A.V. Kuznetsov, A.A. Botaki, in: Y. Chu, T.Y. Hsu, T. Ko (Eds.), Proceedings of the International Shape Memory Alloys Symposium, China Academic Publishers, Guilin, China, 1986, p. 153.

[21] X. Ren, N. Miura, J. Zhang, K. Otsuka, K. Tanaka, M. Koiwa, T. Suzuki, Yu.I. Chumlyakov, M. Asai, Mater. Sci. Eng. A 312 (2001) 196.

[22] Y. Liu, P.G. McCormick, Iron Steel Inst. Jpn. Int. 29 (1989) 417. 